\title{
THE LITTLE SCHOOL POR ALICIA PARTNOY EL TESTIMONIO EN LA ARGENTINA
}

\author{
POR
}

\author{
MARTA BERMUDEZ-GALLEGOS \\ Rutgers University
}

... no se puede saber hasta donde nos han envenenado los adentros, hasta donde hemos sido mutilados en la conciencia, la identidad y la memoria.

Galeano, 1988

\begin{abstract}
Durante el día los militares andaban por los torrentes de las calles, con los pantalones enrollados a media pierna, jugando a los naufragios con los niños. En la noche, despues del toque de queda, derribaban puertas a culatazos, sacaban a los sospechosos de sus camas y se los llevaban a un viaje sin regreso. Era todavía la búsqueda y el exterminio de los malhechores, asesinos, incendiarios y revoltosos del Decreto Número Cuatro, pero los militares lo negaban a los propios parientes de sus victimas, que desbordaban la oficina de los comandantes en busca de noticias. 'Seguro que fue un sueño', insistían los oficiales. 'En Macondo no ha pasado nada, ni está pasando ni pasará nunca. Este es un pueblo feliz.
\end{abstract}

Escenas similares a las descritas en la ficción profética del discurso de Cien años de soledad ${ }^{1}$ se volvieron realidad cotidiana en América Latina durante los años setenta y ochenta. A pesar de nombres y lugares diferentes, las rutinas y los métodos utilizados al igual que los resultados fueron los mismos. En el transcurso de un año desaparecieron en Chile entre 5,000 y 30,000 personas; en siete años el mismo destino sería compartido por 30,000 argentinos; y en la pequeña nación vecina del Uruguay, de cada 500 ciudadanos, uno sería encarcelado y nunca volvería a saberse el paradero de la mayoría de dichos prisioneros. Aplicando la doctrina panamericana de la Seguridad Nacional, los militares actuaron como un ejército de ocupación en sus propios países, sirviendo al Fondo Monetario Internacional y al sistema de privilegios que el Fondo expresa y perpetúa ${ }^{2}$.

${ }^{1}$ Versión revisada de un trabajo lédo en la convención de NEMLA en Abril de 1988.

${ }^{2}$ Aclaremos aquí que decimos ficticias como parte de la naturaleza del relato en Cien años ... (p. 263 ed. 1973) ya que se reconoce como referente el incidente real de la masacre de Santa María en 1928 durante la cual perecieron cientos de obreros huelguistas de la United Fruit Company. Durante dicho incidente dirigentes comunistas de los sindicatos 
En el siguiente ensayo presentaremos un análisis del testimonio $L a$ escuelita de Alicia Partnoy dentro del contexto de la dictadura militar argentina durante los años 1976-1983. Durante el auto-denominado Proceso de Reorganización Nacional, el gobierno militar pretendió silenciar, a través del discurso de la violencia, la censura y las tácticas patrioteras del "olvido"3. La clase media, mediante una ceguera espeluznante ante el abuso oficial, pareció colaborar con el discurso del proceso. En medio de tal contexto, cualquier tipo de disidencia era condenado como "el cáncer" que corroe al país y por lo tanto las desapariciones, al orden del día, eran percibidas como la medicina necesaria para que reinara la paz, ya que si un vecino desaparecía era inmediatamente una indicación de su culpabilidad (Corradi, 1-12). Por lo tanto, el terror se había apoderado del recinto cotidiano: la casa, el barrio, la escuela, el trabajo. En el contexto de la opinión pública, se había anulado el discurso. El pueblo había sido despojado de una cultura política.

Ante el discurso del poder oficial, surgió la urgencia de otro discurso que revelará la lucha por el poder de la palabra. En respuesta, los escritores y artistas argentinos encontraron un modo de expresión desde un espacio marginal que se oponía al intento institucional de eliminación de toda oposición; un intento a eliminar "la otredad" (Masiello, 12). La incursión fascista en la experiencia emocional de la cotidianeidad tendrá un efecto cataclísmico que se reflejará en la cultura nacional, y, por ende, en la simbolización social producida bajo las condiciones de extrema represión que dicho régimen impone (Vidal 2). El resultado de dicha disrupción de la cotidianeidad en la producción simbólica argentina de los últimos diez años se expresa como "una preocupación obsesiva por el problema de la historia. nacional, proyectada como una serie de fragmentos que perplejan y que difícilmente pueden organizarse discursivamente”, dice Marta Morello Frosch con referencia a las biografías fictivas producidas durante la misma época(60).

Como veremos en nuestro análisis, la fragmentación discursiva tiene su razón de ser en el interior de la realidad representada. Dentro de "la cultura parentética" que emerge durante los años del "Proceso" la fragmentación adquiere coherencia. Dentro de la escritura de dicho período histórico, no se

obreros fueron el blanco de persecusiones y aprisionamientos. Para consultar un breve dato acerca de este tema véase Hobart A. Spaulding Jr., Organized Labor in Latin America: Historical Case Studies of Workers in Dependent Societies . New York: New York University Press, 1977) 66-67. Para un recuento más detallado, consúltese: Charles David Kepner y Henry Soothill, The Banana Empire. New York: n.p, 1935, capítulo 12 .

${ }^{3}$ Los datos fueron tomados de declaraciones otorgadas a través del Departamento de Estado de los Estados Unidos y obtenidos, a su vez, por monitores independientes como la Comisión Pro Derechos Humanos de la Organización de Estados Americanos, Amnistía Internacional y Américas Watch. Dichos hechos han sido ampliamente documentados y corroborados por todas las agencias mencionadas. 
puede dejar a un lado el discurso testimonial de las víctimas mismas del avasallamiento fascista porque revela el camouflage en la estructura estatal

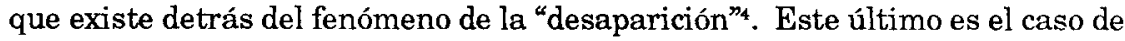
La escuelita de Alicia Partnoy, relato que presenta justamente las características del género testimonial que ha generado numerosas polémicas acerca de su "literariedad" y que tiene como función histórica el desacreditar el discurso de la autoridad que negó hasta el último momento sus prácticas dantescas ${ }^{5}$.

La escuelita se configura como la representación discursiva de una experiencia vivencial que comunica la tragedia compartida por miles de latinoamericanos, ya que "la desaparición" es el arma más efectiva utilizada por regímenes represivos en contra de sus ciudadanos. A la vez, el testimonio de Partnoy continúa la lucha por el poder de la "otredad" silenciada por la dictadura, desarticulando el discurso que durante su tiempo en el poder

\footnotetext{
${ }^{4}$ Aquí nos referimos a las tácticas utilizadas por el régimen militar de alterar al máximo el equilibrio social y las relaciones entre la esfera pública y la privada ocasionando lo que denomina Guillermo O'Donnell, "la cultura del miedo" y que tiene como función clausurar" los canales de transmision de experiencias comunes" y bloquear también "las redes de la memoria colectiva". Véase el trabajo de Beatriz Sarlo, "Política, ideología y figuración literaria", en Ficción y Política. La narrativa argentina durante el proceso militar. Además del terror recordemos otras maniobras "patrioteras" utilizadas para distraer la atención pública, la economía artificial de "la plata dulce", el Campeonato Mundial de Fútbol del 78, la censura de todo aquello que no es "lo nuestro", entre otras, llegando al colmo ( $\mathrm{y}$ a su fin) con la Guerra de Malvinas en 1982.

${ }^{5}$ Véase el trabajo de Guillermo O'Donnell, "Tensions in the Bureaucratic-Authoritarian State". En David Collier ed, The New Authoritarianism in Latin America, el cual, en la década de los setenta señaló que la supresion de los "otros" es conseguida eficazmente mediante la presencia de una voz disfrazada detrás de un "nosotros" creado por el estado. Este "nosotros", según O’Donnell, sirve "para permitir a las instituciones del estado aparecer como agentes que logran y protegen un interés general". Dentro de este "camouflage" las desapariciones son rotundamente negadas, incluso hasta en la actualidad, y tienen la función de deshumanizar a los "otros" a través de la "no existencia".

${ }^{6}$ Debido a que ya a mediados de los años sesenta, la Revolución Cubana mediante su acceso a aparatos culturales de difusión, legitimiza "el testimonio" dentro de los ámbitos académicos y culturales, llegando a un respetado establecimiento al ser integrante de las categorías oficiales concursantes para el Premio Casa de las Américas en 1970, existe ya una bibliografía respetable acerca de las meditaciones sobre la configuración discursiva del discurso testimonial. Para una sintesis crucial de las teorías elaboradas en Estados Unidos acerca de dicho discurso, consúltense: René Jara y Hernán Vidal, eds., Testimonio y Literatura, Minneapolis, Institute for the Study of Ideologies and Literatures, 1986; Eliana Rivero, "Acerca del género 'Testimonio': Textos, narradores y 'artefactos", Hispamérica, 1988; Hugo Achugar, "Notas sobre el discurso testimonial latinoamericano"; John Beverley, "Anatomía del testimonio", Revista de Critica Literaria Latinoamericana, 25 (1987) pp. 7-16, incluido en su libro Del Lazarillo al sandinismo, Minneapolis, 1987, pp. 153-168; Roberto González Echevarria, Biografía de un cimarrón and the Novel of the Cuban Revolucion.
} 
destruyó totalmente el seno de la cotidianeidad argentina, la esencia misma de aquello que nos define como seres humanos.

Desde sus origenes muy cercanamente al momento de la Conquista, la tradición discursiva testimonial en América Latina se ha perfilado como dos discursos intrahistóricos en confrontación ${ }^{7}$. En el momento de enfrentamiento con la "otredad" se configura la polarización discursiva en dos direcciones: la de los dominantes y la de los dominados. A pesar de que la evolución de dichos discursos es simultánea y de un desarrollo sumamente complejo, encontramos que en la experiencia de las últimas décadas dicha polarización se continúa y, lo que es más, se acentúa en el contexto de regímenes totalitarios. Por ambas partes "la verdad" del avasallador dista en términos semánticos y lingüisticos de aquella "verdad" marginada, de los “avasallados" (Prada Oropeza 7). Por razones obvias, históricamente el testimonio de los dominadores se ha expandido mucho más y por lo tanto es más conocido que el de los dominados debido a que el primero ha sido siempre considerado como parte integral de la cultura oficial y de aquellos que comparten el poder ${ }^{8}$.

Dentro de la marginación encontramos que el discurso femenino es, como a todo otro nivel de explotación, doblemente marginado y, a su vez, doblemente censurado. Incluso, hoy día, en que se supone que la mujer ha logrado un acceso mayor a los medios de difusión, el discurso testimonial latinoamericano femenino, convencionalmente publicado, no parece haber logrado difundirse tanto como su equivalente masculino. Con excepción de Domitila Barrios, Rigoberta Menchú, y Claribel Alegría a las que últimamente se les ha prestado mayor atención, poco se ha meditado en ambientes intelectual-académicos acerca del discurso testimonial femenino. Por esa y por muchas otras razones, hemos escogido el testimonio de una mujer para analizar dicho discurso en relación a la desaparición en la Argentina?.

${ }^{7}$ La descripción de la tradición histórica en que se inserta el relato testimonial ha sido verificada a través de la contribución de críticos como Angel Rama, Roberto Fernández Retamar, Carlos Rincón, Renato Prada Oropeza, René Jara, Jaime Concha, Juan Duchesne o el propio Miguel Barnet.

${ }^{8}$ Hugo Achugar sintetiza el germen de la literatura testimonial en "Notas sobre el discurso testimonial latinoamericano" al decir lo siguiente respecto a la lucha por el poder: “... la historia de Hispanoamérica, del Brasil y de las Antillas ha estado siempre signada por dicha lucha. Una de las vías en la conquista del poder y del discurso es el control de la producción simbólico-discursiva. Si bien se pueden observar distintas etapas en las que el discurso es de resistencia, o de desarticulacion frente al discurso del sector en el poder; en definitiva, todo discurso aspira al poder" (p. 3).

${ }^{9}$ Especificamos "publicado convencionalmente" porque no hay que olvidar que el movi. miento de mayor impacto en su lucha contra el terrorismo oficial durante las dictaduras militares y en defensa de los derechos humanos fue el de "las Madres" y sus testimonios. Inicialmente, el movimiento argentino de Plaza de Mayo, al cual implícitamente rinde homenaje el texto de Partnoy, y luego sus contrapartidas en Chile, EI Salvador,y Guatemala. Es a través del testimonio y lucha activa de las Madres por rescatar del anonimato a sus hijos "desaparecidos" que se combate la posibilidad de una amnesia histórica de parte del estado. 
Manteniendo la premisa de que el discurso testimonial latinoamericano se inicia como una veridificación de la realidad en constante pugna con discursos de condición represiva, entraremos en la Argentina de los años 1976-1983, los cuales son de un impacto decisivo en toda la creación literaria que ocurre durante ese periodo y posteriormente. Como se mencionó al principio, el discurso de la autoridad pretendió silenciar al discurso de "la otredad" con una percepción única de la realidad eufemizando el esfuerzo tras la máscara "que combina lo que se quiere decir con lo que se puede decir". A través del discurso de la censura se controla lo que se quiere decir y sólo filtra lo decible. La censura no comienza con el proceso; es parte integral de éste y es, en realidad, un proceso en sí mismo que podría decirse comienza en los años treintas, y que en mayor o menor grado se acentúa a partir del año 1960 cuando comienza "la guerra ideológica". Dicha censura se organiza lentamente por veinticuatro años y alcanza la etapa de aceleración en 1974 (Avellaneda, pp.29-30).

Ante este discurso oficial, perpetrado en nombre de Dios, la patria y la familia, encontramos múltiples y plurales respuestas de parte de los artistas e intelectuales que establecen un espacio político alterno a través del cual "se transforma la oposición binaria de dominadores y oprimidos con el propósito de fragmentar cualquier discurso unificadoque pueda apoyar al estado autoritario o aislar irremediablemente al 'otro"' (Masiello, 13). Además, aquellos desaparecidos que sobrevivieron la captura y los vejámenes a los que fueron sometidos tienen la obsesiva necesidad de comunicar y denunciar la experiencia. Dicha necesidad se hace aparente en la ficción discursiva de la última década al igual que a través del discurso testimonial. En las palabras de Ariel Dorfman acerca del discurso testimonial en Chile se sintetiza la razón para la urgencia de compartir la experiencia:

Si el proceso revolucionario chileno y las décadas de lucha democrática previa le concedieron a estos hombres la sensación de su propia humanidad, lo que el fascismo le ha brindado - regalo duro y bestial es la conciencia de haber pasado por una prueba victoriosamente, de haber defendido y desarrollado ese derecho a llamarse humanos. Cada testimonio ... prolonga un cierto concepto del hombre y de la mujer opuesto al que ejercitan y cultivan los torturadores. Haber cumplido con el deber, haberle dado un sentido y una razón a la cólera sufrida y a la humillación, se convierte en la secreta fuente de tantos relatos, una forma muy concreta de reiterar la superioridad ética frente al totalitarismo (173).

La dedicatoria del testimonio: "In memory of Daniel, my brother, for whom life became so absurd that he decided to take his own" es la primera pauta de la devastación personal y familiar de la experiencia que se va a relatar. La introducción, en primera persona, relata los acontecimientos históricos desde el punto de vista personal, en el año 1984, cuando la autora regresa a la Argentina después de cuatro años y medio en el exilio: 
to mourn my friends who had disappeared or were killed by the military, to mourn the members of my family who had died during my ordeal of seven years in prison and banishment, and to suffer at the sight of my country ruined after years of dictatorship.

En dicha introducción se presenta una síntesis histórica de los hechos que llevaron a la juventud (y a la autora) a abrazar al peronismo, cómo el peronismo decepcionó las expectativas populares y la llegada de los militares con desapariciones previas y posteriores a su llegada. La narradora, en un estilo periodístico, casi judicial, que asegura la localización temporal y espacial de los acontecimientos, describe someramente su estadía en la Argentina, sus declaraciones frente a la CONADEP, los resultados jurídicos mínimos de las investigaciones:

Despite overwhelming evidence, one year later only two military leaders ... have been given life sentences ... only three others have been convicted, and four military leaders were acquitted of all the charges. The rest of the criminals enjoy freedom ... (17).

Además, la reunión con dos Madres de dos-cómpañeras desaparecidas y la hijita de cuatro años de una de ellas, activas en la búsqueda de sus hijos y en la lucha por sus derechos, sirve como punto de origen y motivación para comenzar a narrar. A partir del encuentro la narradora establece la función testimonial de su relato:

The voices of my friends at the Little School grew stronger in my memory. By publishing these stories I feel those voices will not pass unheard ... Today while sharing this part of my experience, I pay tribute to a generation of Argentines lost in an attempt to bring social change and justice. I will also pay tribute to the victims of repression in Latin America(18).

Creo importante destacar la división que observara Margaret Randall de "testimonio en si" y "testimonio para si", ya que es en la segunda de las categorías que se basa el germen del testimonio de Alicia Partnoy, autopostulado como un tipo de texto con intenciones poéticas propias ${ }^{10}$. Estructuralmente es una obra bastante compleja porque, por una parte, la función testimonial cobra hegemonía pero, por otra, predomina el lenguaje poético a través de recursos particulares a ese lenguaje: la elipsis, la reiteración, el paralelismo, la intertextualidad, a través de la inserción de fragmentos de poemas de otros autores latinoamericanos y españoles a manera de epígrafes.

\footnotetext{
${ }^{10}$ Margaret Randall, ¿Qué es el testimonio?. Serie de cuatro charlas mimeografiadas de M. Randall, ofrecidas en el Ministerio de Cultura de Nicaragua como parte de un seminario de capacitación, en octubre de 1979.
} 
El enunciado se vale de diferentes códigos que confieren al relato una textualidad que nos atrevemos a denominar como "textil", o tal vez mejor, "centónica" ya que se asemeja a las estampas dibujadas con retazos por la actual artesanía chilena de las arpilleras o a los centones decimonónicos tan comunes en la artesanía femenina norteamericana ${ }^{11}$. La narración, consistente de veinte viñetas, se encuentra enmarcada por un prefacio escrito por Bernice Johnson Reagon, una introducción por la autora, y dos ápendices posteriores acompañados de un croquis de la "escuelita" que nos recuerdan a los reproducidos por la CONADEP en su informe, titulado, Nunca más. La disposición del enunciado funciona como recurso composicional ya que, para comunicar la realidad satanesca de la experiencia vivida, es preciso desjerarquizar la narración. Dicha desjerarquización no disminuye el valor de los elementos discursivos sino que valora a todos de la misma manera ${ }^{12}$. El lenguaje se encarga de comunicar, en dicho discurso desjerarquizado, la fragmentación en cuanto a tiempo y espacio de la vida antes, durante y después de la “desaparición”. Los espacios, signos lingüísticos en sí mismos, se encargan de transmitir el terror en el silencio mismo. Los objetos cotidianos proveen el hilo que brinda continuidad al discurso.

En la introducción, la narradora-testigo prepara al lector para entrar en la narración a través del recurso de reproducción completa mediante el cual es difícil separar la realidad de la imaginación:

I knew just one Little School, but throughout our continent there are many "schools" whose professors use the lessons of torture and humiliation to teach us to lose the memories of ourselves. Beware: in little schools the boundaries between story and history are so subtle that I can hardly find them(2).

\footnotetext{
${ }^{11}$ Como parte de la resistencia chilena a la dictadura militar, las familias de los desaparecidos han creado un tipo de artesanía textil que se asemeja a un "collage" que cuenta la historia de la desaparición. Dicho cuadro se confecciona utilizando un trozo de arpillera en la que se zurcen retazos de tela que en la mayoría de los casos ha pertenecido a la ropa del familiar desaparecido. Para una version más detallada acerca de este fenómeno chileno, consúltese Marjorie Agosin, The Scraps of Life.. La artesanía de las arpilleras se ha difundido por varios países de América Latina. En el Perú, el Centro Flora Tristán en colaboración con mujeres de los "Pueblos Jóvenes" ha comenzado la misma tradición artese al para difundir las penurias por las que se pasa en el cotidiano vivir con la pobreza.

${ }^{12}$ Es singular notar que, dentro de la crítica femenina en los Estados Unidos, existe una extensa biliografía acerca del fenómeno del discurso literario configurado como un "centón verbal", refiriéndose a la tradición artesanal femenina del mismo país. Véase, "Piecing and Writing" en Nancy K. Miller, ed. The Poetics of Gender. Raquel Blau Du Pleiiss, "For the Etruscans" en The New Feminist Criticism, Ed. Elaine Showalter, 1985, sostiene que la escritura puramente femenina tiende a ser: "nonhierarchic ... breaking structures, making an even display of elements over the surface with no climatic place or moment, having the materials organized into many centers". En el texto femenino no hay "subordination, no ranking". (p. 274).
} 
La función de dicho recurso poético es preparar al lector para la odisea kafkiana que se avecina en el discurso enmarcado. Las viñetas, dispuestas como estampas de "la arpillera" en el discurso enmarcado, se encargarán de comunicar la experiencia de la desaparición en su totalidad.

El discurso enmarcado comienza con unailustración por la madre de Alicia, Raquel Partnoy, que representa, en un código gráfico, tres prisioneros, desmembrados, con los ojos vendados con una venda transparente. Detrás de los prisioneros, sumidas en una total oscuridad, se pueden notar cuatro máscaras observándolos. La ilustración, elemento activo de la estructura del discurso, da la pauta de que, a pesar de la negación total del estado, las cárceles existieron. Y que de dichos centros clandestinos, a pesar de la mutilación física y sicológica, saldrán los testimonios de aquellos pocos que tuvieron la oportunidad de sobrevivirla. La ilustración precede una página en blanco, el título: The Little School, otra página en blanco y una cita del Documento Final de La Junta Militar sobre la Guerra Contra la Subversión yel Terrorismo, la cual ha sido ya refutada por la introducción al texto e ilustración de Raquel Partnoy y continuará siendo refutada por los acontecimientos narrados:

There is also talk of 'disappeared' persons who are still held under arrest by the Argentine government in unknown places of our country. All of this is nothing but a falsehood stated with political purposes, since there are neither secret detention places in the Republic nor persons in clandestine detention in any penal institution"(4).

Como se había establecido al principio de este estudio y como se puede observar en el "epígrafe", el "intertexto" en pugna con el discurso del poder se halla presente en La escuelita y servirá para recrear la realidad en el resto del discurso. El discurso aquí presente, como muchos otros discursos testimoniales, alcanza cierta plenitud en un lenguaje mixto, de texto lingüisticamente articulado, de lenguaje gráfico visual (con las ilustraciones de la madre de Alicia) y de espacios en blanco simbolizando el silencio al que, incluso, se llegó a temer. Pero, La escuelita ha sido escogida como ejemplo de un testimonio argentino porque en ella se distingue una polifonía de voces y silencios que presentan una imagen totalizante de la experiencia de la desaparición. La narradora-testigo se desplaza desde la tercera persona narrativa, a la primera persona singular a la primera persona plural; transitando de la corriente de la conciencia a la narración descriptiva y asumiendo voces de diferentes participantes en la experiencia del cautiverio. De acuerdo con Ariel Dorfman, la pluralización del sujeto narrante (implícita o explícitamente) en primera persona, es una de las características definitorias del discurso testimonial y, a la vez, una muestra de su dignidad y cita a Henri Alleg: "En esta inmensa prisión sobrepoblada, en la que cada célula abriga un sufrimiento, hablar de sí mismo es como una indecencia" (1958, Introduction). 
En la viñeta titulada: "Graciela: Around the Table", desde la "vozconciencia" de Graciela, compañera de cautiverio y buena amiga de la narradora-testigo desde antes de éste, escuchamos el grito agonizante de la mujer que, habiendo sido torturada desde su quinto mes de embarazo, tiene que dar a luz en ese encierro. Estos son sus pensamientos, en segunda persona singular, mientras, para hacer "ejercicio", da vueltas alrededor de una mesa en los últimos momentos del embarazo:

The child is moving ... my love, to protect you, my dear child? Me?... so unprotected myself. If only your father were here. Perhaps you could hear his whispers, 'Be strong my child, take heart ... The future is yours.' Your future, my child ... we gave up sunshine on our skin for your future ... The thirtieth round of this living death. Don't forgive them, my child. Don't forgive this table, either" (56).

Este caso remite a la introducción, ya que una de las Madres con la que se encontró Partnoy era la madre de Graciela. El destino sufrido por Graciela y por su hijo nacido en cautiverio aún no es conocido.

Otro ejemplo de la pluralización se encuentra, más tarde, en el capítulo titulado: "Ruth's father". Otra vez en segunda persona del singular, la narradora-testigo nos lleva a la conciencia del padre de su hija quien resiste la tortura hablándole mentalmente a la niña, partiendo de una canción infantil popular en la Argentina: 'El sapito Glo-glo-glo:

Daughter, dear my tongue hurts and I can't say "rib-it rib-bit; even if I could, you wouldn't hear me. This little poem soothed you when you cried; you went to sleep listening to it ... I've repeated it for a whole day but I still can't sleep Rib-bit ribbit he sings on the roof ... I won't see you again ... The electric prod on my genitals ... Trapped, like the little frog ... 'but we hear him all the time' ...(93).

Como pudimos apreciar en los dos ejemplos anteriores, la necesidad de mantener un lazo unificador en la cotidianeidad se expresa a través de las comunicaciones mentales con el centro del recinto familiar que, para aquéllos que son o están a punto de ser padres, es el hijo. Hasta este momento se ha notado en los ejemplos dados el uso de un lenguaje poético de elipsis metafórica, reiteración, espacios en blanco en la disposición tipográfica, que sumados a los objetos cotidianos nombrados, añade a la ternura y al sentido humano con que se transmite la experiencia de supervivencia y camaradería de una de las tantas jóvenes que fueron arrancadas de sus hogares para ser "purgada" a fuerza de humillaciones, tortura, violaciones, y la falta de los más básicos elementos higiénicos para mantener una mínima salud mental y física. El nombrar aquellos objetos (las chancletas, el pan, su diente guardado en una cajita de fósforos, la campera de Vasca la cual servirá como refugio a la narradora-testigo 
para soportar la desaparición de su amiga) que enlazan la vida de afuera con el cautiverio, parece ser el refugio ante la locura. Se intercambian trozos de pan, símbolo de vida y objeto precioso en el cautiverio, para demostrar camaradería en un ambiente en el cual las palabras entre compañeros eran causa suficiente para instigar palizas, torturas y muertes. A la vez, ese nombrar es el arma para mantener hilvanando los trozos del ámbito cotidiano que el enemigo trató de destruir. La narradora testigo sabe que si sus pensamientos del hogar, la familia, los amigos se logran destruir por el ambiente de gritos, risotadas, golpes y humillaciones constantes, está perdida. En el testimonio de Viktor Frankl de los campos de concentración nazis, Man's Search For Meaning encontramos los mismos recursos de supervivencia utilizados por él y por sus compañeros en momentos en que el frío, la brutalidad de los guardias. el dolor, y el trabajo forzado se prolongaba por muchas más horas de las soportables por un cuerpo saludable. Las condiciones deplorables bajo las que se mantenian a estos prisioneros no nos hacen suponer que dichos cuerpos se encontraran en un estado que pudiera asemejarse a uno de "buena salud":

In spite of all the enforced physical and mental primitiveness of the life in a concentration camp, it was possible for spiritual life to deepen ... In order to make myself clear I am forced to fall back on personal experience ... But my mind clung to my wife's image, imagining it with an uncanny acuteness. I heard her answering me, saw her smile, her frank and encouraging look. Real or not, her look was then the sun which was beginning to rise (55-57).

El vínculo con la esposa, tal como hemos observado, sirve al prisionero de los años cuarenta como recurso para soportar el dolor y, últimamente, sobrevivir. En el año 1976, la experiencia del campo de concentración se repite y en una de las viñetas de La escuelita, titulada "Telepathy", la protagonista se desespera por establecer comunicación con su familia a través de la telepatía, después de intentarlo dos veces sin éxito, en un momento en que logra concentrarse por tercera vez, en su mente imagina la casa de sus padres y a estos, haciendo el té en la cocina, su hermano inclinado leyendo un libro, "The sunlight ... the trees in the backyard. 'I'm okay,' I repeated in my mind. 'I'm alive. I'am alive. I'm still alive"' (p. 50).

El intertexto es explícito e implícito en el caso de La escuelita, ya que los espacios comunican varios niveles de realidad que se funden en una ironía que, a pesar de la ternura aparente, emiten un mensaje agrio y cáustico. Encontramos, por ejemplo, como intertexto implícito el testimonio de Jacobo Timmerman, quien percibe su captura exclusivamente como antisemitismo, mientras que Partnoy declara lo siguiente:

Now that Chiche has come out with the 'discovery' of my Jewishness, I realize this is the first time the subject of my race has come up here. When I was 
interrogated the guards didn't mention it at all. In any case it's not for being Jewish that I was brought to the Little School. Nestor and Mary weren't brought here because they are Christian either. jSo many priests have blessed the weapons of the military! So many rabbis thank God for the coup that has saved them from "chaos!" Whenever things like this happen, I'm convinced that God is just a pretext ... and I instinctively reject pretexts (p. 63) ${ }^{13}$.

Los apéndices que se encuentran al final de la novela y que sirven como marco al relato tienen como función personalizar a las víctimas y victimizadores, que se conocieron a través de la narración, ya no en un lenguaje literario, sino en un lenguaje periodístico casi notarial. Este tipo de lenguaje asegura al lector que la existencia de estos seres de carne y hueso, con nombres y apellidos, fue real. Dicho recurso descarta la posibilidad de confusión de que todo el relato haya podido ser una ficción.

Como establecimos al principio, el discurso testimonial se perfila como un discurso en confrontación con la "otredad" en una lucha continua por el poder. No es casual, por lo tanto, que dados los acontecimientos de los últimos veinte años en el cono Sur, en Centroamérica y en el Brasil, este género haya proliferado del modo que lo ha hecho. La característica innegable del discurso testimonial, como lo han sugerido y establecido críticos como Hugo Achugar, René Jara y otros colaboradores en Ideologies \& Literatures es que manifiesta la tematización de la lucha por el poder. De acuerdo con Achugar y referente al texto de Omar Cabezas, La montaña es algo más q'ue una inmensa estepa verde:

la conquista y la producción del poder ... no es meramente un tema o el tema fundamental sino que es una acción realizada por el propio discurso .... Testimonio como es sabido viene de testimoniar: es decir, de un acto de habla que realiza la propia acción de construir una realidad discursiva. Y en este caso tal como ha sido observado por la mayoría de los críticos el término realidad tiene un sentido fuerte (3).

El texto de Omar Cabezas termina con la oración: "Me sentí invencible. Agosto/noviembre de 1981"; o sea, después del triunfo de la Revolución Sandinista y, -como dice Achugar, es una frase pronunciada "ya desde el poder". Sin embargo, es un discurso que se percibe e interpreta de diferente manera que otros discursos desde el poder, ya que lo pertinente de este último discurso testimonial, de acuerdo con Achugar, no es tanto la estrategia discursiva sino la posición ideológica asumida por el sujeto emisor ("yo/nosotros: el pueblo") establecida en el discurso y dirigida al receptor (yo/nosotros: el pueblo). El

\footnotetext{
${ }^{13}$ Debemos informar, sin embargo, que de acuerdo con los testimonios publicados en el informe de la CONADEP, Nunca más, los ciudadanos judíos secuestrados y detenidos en cárceles clandestinas eran tratados con mayor rigor que el resto en algunos casos. El judaísmo se utilizaba como objeto de mofa y arma de humillación (1985, pp. 26-27).
} 
discurso testimonial se enuncia desde el contexto histórico creando "una interdiscursividad histórica que establece las diferencias y delimita el carácter de cada enunciación" (3-5).

Tenemos luego en La escuelita de Partnoy un caso en el que el sujeto de la enunciación intenta desde el principio establecer la historicidad narrativa, no desde el poder, sino luchando por éste a través de la refutación del discurso de la autoridad, estableciendo la interdiscursividad histórica para asegurarse de que el lector no tendrá ninguna duda de la veracidad del relato. La posición de Alicia Partnoy es similar al caso citado por Achugar, Las manos en el fuego, de Ernesto González Bermejo, en cuanto a su posición en relación al poder: “derrotada pero no vencida” (1988, p. 5). El discurso le otorga el arma necesaria para proseguir la lucha y para asegurarse, a través de su refutación del discurso oficial, que los acontecimientos relatados no vuelvan a ocurrir. El discurso de la autoridad en la Argentina durante el Proceso de Reorganización Nacional: propaganda en periódicos, afiches, calcomanías, documentos; todas las herramientas utilizadas por el elemento opresor para dirigir y censurar la cultura argentina y que sirven como intertexto a los testimonios ya mencionados no pueden ser olvidadas. Dicho discurso merece ser investigado y contrastado con los testimonios para que la pauta quede establecida para la posteridad de que esos argentinos, que hicieron del país un lugar donde acechaba la muerte cotidianamente, no fueron ni "derechos" ni "humanos"14.

El testimonio de Alicia Partnoy se dispone discursivamente como una gran "arpillera" textual hilvanando de manera desjerarquizada toda la experiencia de una familia víctima de la dictadura argentina. Los elementos interrelacionados dinámicamente en la construcción de este discurso se han explicitado desde el diálogo entre el discurso oficial y el testimonio, desde el discurso poético hasta el notarial, desde la polifonía hasta el tejido de lo cotidiano con lo histórico, separando la realidad de la imaginación. A través de una estructura sencilla a primera vista, pero altamente elaborada en última instancia, La escuelita consigue comunicar la tragedia argentina (latinoamericana) de los ultimos años, insinuando imágenes de la obscenidad del "Proceso" sin necesidad de perder la dignidad al detallarla. Por lo tanto, Alicia Partnoy demuestra, en su testimonio, una integridad opuesta a la inmoralidad de los torturadores, ya que, volviendo a las palabras de Dorfman, le ha “... dado un sentido y una razón a la cólera sufrida y a la humillación ... demostrando su superioridad ética frente al totalitarismo".

\footnotetext{
${ }^{14}$ Aquí nos referimos al eslogan creado y utilizado como propaganda por la Junta durante el período de investigación de las violaciones cometidas en la Argentina por parte de organismos internacionales: "Los argentinos somos derechos y humanos".
} 


\section{OBRAS CITADAS}

Achugar, Hugo. "Notas sobre el discurso testimonial latinoamericano", ponencia leída en el XXVi Congreso del Instituto Internacional de Literatura Iberoamericana y publicada en las Memorias del mismo editadas por Raquel Chang Rodr iguez y Gabriella de Beer bajo el título de La historia en la literatura iberoamericana. Ediciones del Norte, 1989 pp. 279-294.

Agosín, Marjorie. Scraps of Life: The Chilean Arpilleras. Trans. Cola Franzen. New Jersey, Trenton: The Red Sea Press, 1987.

Avellaneda, Andres. "La ética de la entrepierna: control censorio y cultura en la Argentina". Hispamérica 1986 April; 15.

(43): $29-44$.

Corradi, Juan. The Fitful Republic. Economy, Society and Politics in Argentina . Boulder, Colorado: Westview Press, 1985.

Comisión Nacional Sobre La Desaparición De Personas. Nunca más. Buenos Aires: Editorial Universitaria, 1985.

Jara, René y Hernán Vidal, eds. Testimonio y Literatura.. Minneapolis: Institute for the Study of Ideologies and Literatures, 1986.

Kepner, Charles David y Henry Soothill. The Banana Empire New York: n.p., 1935

Masiello, Francine, "La Argentina durante el Proceso: Las Múltiples Resistencias de la Cultura". Ficción y Política. Buenos aires: Alianza Estudio. 1987.

Morello Frosch, Marta, "Biografías fictivas: formas de resistencia y reflexión en la narrativa argentina reciente". Ficción y Política. Buenos Aires: Alianza Estudio. 1987.

O'Donnell, Guillermo, "Tensions in the Bureaucratic-Authoritarian State". En David Collier (compilador), The New Authoritarianism in Latin America.. Princeton: Princeton University Press, 1978.

Partnoy, Alicia. Trans. Alicia Partnoy, Lois Athey and Sandra Braunstein. The Little School. San Francisco: Cleis Press. 1986. 
Prada Oropeza, Renato. "De lo testimonial al testimonio: Notas para un deslinde del discurso testimonio" en Testimonio y Literatura.. Minneapolis: Institute For the Studies of Ideologies and Literature, 1986.

Randall, Margaret. ¿Qué es el testimonio?. Conferencia en Managua, 1979.

Sarlo, Beatriz. "Política, ideologia y figuración literaria" en Ficción y Política. La narrativa argentina durante el proceso militar. Buenos Aires: Alianza Estudio, 1987.

Spaulding, Hobart A., Jr. Organized Labor in Latin America: Historical Case Studies of Workers in Dependent Societies, New York: New York University Press, 1977. 